\title{
ANALISIS KINERJA NON CDN DAN GEO DNS PADA CDN MENGGUNAKAN NS-2
}

\author{
Sahat Parulian Sitorus ${ }^{1}$, M. Zarlis ${ }^{2}$, Suherman ${ }^{3}$ \\ Magister Teknik Informatika Universitas Sumatera Utara \\ Jl. Universitas No.9A Kampus USU, Medan, Sumatera Utara-Indonesia \\ sahatsitorus3@gmail.com
}

\begin{abstract}
Abstrak-Pengakses jaringan single server pada saat ini meningkat pesat. Ketika banyak pengguna terhubung pada jaringan single server. Ketika single server atau non CDN (non Content Delivery Network) melayani permintaan dari banyak pengguna. Besar kemungkinan server yang melayani akan terjadi overload dan crash. Melihat dari kebutuhan user dan waktu yang diperlukan menjadi hal yang diutamakan adalah kecepatan akses pengirim paket data video streaming sampai kepada tujuan penerima. Geo DNS yang diterapkan adalah salah satu solusi yang efektif dan efisien untuk mengatasi masalah tersebut. Arsitektur CDN ini dibangun dengan menggunakan konsep Network Simulator-2 (NS-2) yang memungkinkan proses pentransmisi paket data video streaming didistribusi dengan cepat ke server terdekat yang melayani permintaan client server. pengujian dan percobaan yang dilakukan maka parameter yang diukur adalah delay dan packet loss. Dari hasil pengujian didapat delay 0,279296 s dan packet loss 44,30 \% non CDN, sedangkan Delay 0,067609 s dan packet loss 4,12\% Geo DNS diterapkan pada CDN. Maka kesimpulannya adalah jauh lebih baik kinerja Geo DNS pada CDN dibandingkan non CDN.
\end{abstract}

Keywords-Kr Non CDN, Geo DNS, CDN, NS-2.

\section{PENDAHULUAN}

Single server atau non CDN (Content Delivery Network) merupakan suatu sistem jaringan satu server untuk didistribusikan paket data video streaming ke banyak pengakses di tiap-tiap negara [1], distribusi non CDN dilakukan dengan tanpa algoritma.

CDN (Content Delivery Network) adalah suatu sistem jaringan server-server untuk mendistribusikan paket data video streaming ke pengakses ditiap-tiap negara agar konten video yang dikirim dan diterima pengguna lebih cepat [2], jadi distribusi CDN dilakukan dengan teknik algoritma.

Algoritma CDN yang sudah digunakan yaitu load balancer, round robin dan weighted round robin sedangkan yang belum ada diselidiki ialah Geo (Geografis) DNS (Domain Name System).

\section{TINJAUAN PUSTAKA}

\section{A. Geo DNS}

Geo DNS adalah teknik membagi dan memetakan pengguna single server menurut lokasinya. Server CDN ditempatkan pada setiap lokasi yang telah dipetakan sesuai dengan pemetaan dan setiap client yang melakukan permintaan video steraming akan dilayani oleh server terdekat [3]. Gambar 2.1 Geo DNS pada CDN sebagai berikut :

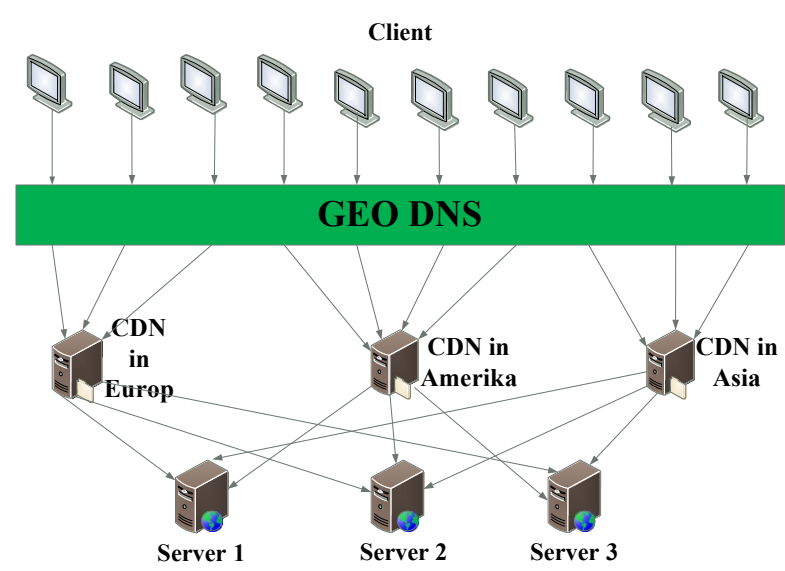

Gbr. 1 Geo DNS

\section{B. Keunggulan Geo DNS}

Geo DNS memiliki keunggulan diantaranya adalah sebagai berikut [4]:

1. Beban server lebih sedikit

2. Mengurangi biaya pengiriman konten video streaming

3. Pengiriman konten video yang lebih cepat

4. Ketersediaan konten video streaming 100 persen 
5. Pengiriman konten video lebih terkontrol menurut wilayah request terdekat.

\section{Lokasi Pemetaan Geo DNS}

Lokasi server CDN dipetakan menjadi 3 server berdasarkan lokasi wilayah server dimasing-masing tiap negara. Gambar 2 Pemetaan Geo DNS pada CDN.

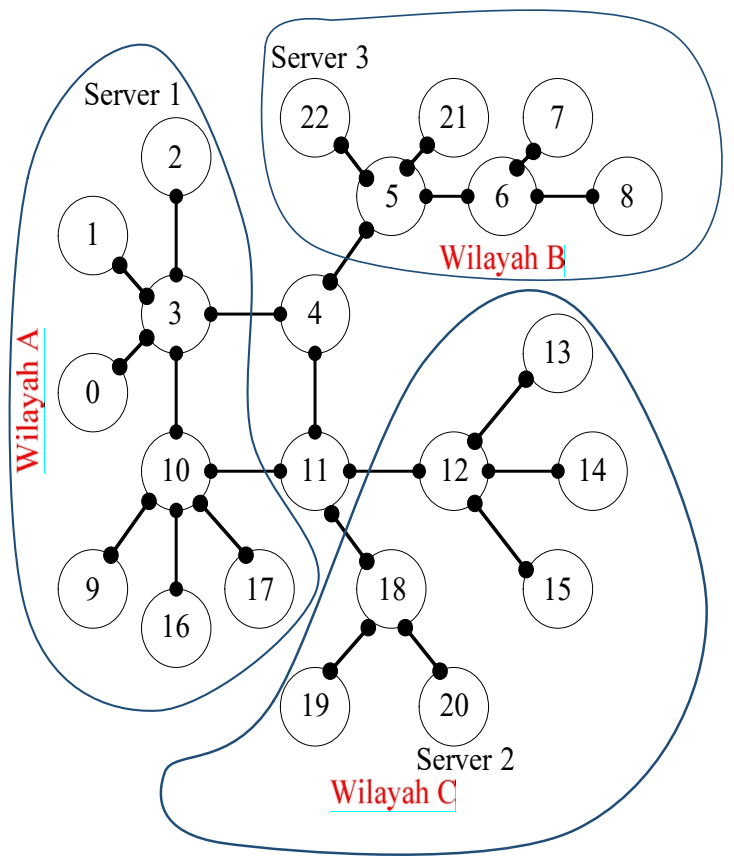

Gbr. 2. Pemetaan Geo DNS pada CDN

Gambar 2 merupakan pemetaan Geo DNS pada CDN yang difungsikan untuk meminimalisir jarak terdekat lokasi antara pengakses (client) dengan server penyedia layanan streaming video online. Pada desain ini dikelompokan lokasi negara berdasarkan benua :

1. Wilayah A : Negara-negara yang berada di Benua Eropa akan dilayani oleh server yang berlokasi di negara Inggris.

2. Wilayah B : Negara-negara yang berada di Benua Amerika akan dilayani oleh server yang berlokasi di negara Amerika.

3. Wilayah C : Negara-negara yang berada di Benua Asia akan dilayani oleh server yang berlokasi di negara Singapura.

D. Network Simulator-2 (NS-2)

NS-2 adalah perangkat lunak simulasi jaringan yang banyak digunakan dalam mempelajari struktur dinamika dari jaringan komunikasi. NS-2 mampu mensimulasikan jaringan kabel/ LAN (Local Area Network) dan jaringan nirkabel/ WLAN (Wireless Local Area Network).

Gambar 2.4 dibawah ini menunjukan arstektur dasar NS-2. NS-2 menggunakan dua jenis bahasa pemrograman, $\mathrm{C}++$ dan TCL. $\mathrm{C}++$ digunakan sebagai cre proses simulasi, sementara TCL untuk konfigurasi jaringan. NS-2 bersifat open source di

bawah GPL (Gnu Public License) dapat digunakan pada sistem operasi windows dan sistem operasi linux[5].

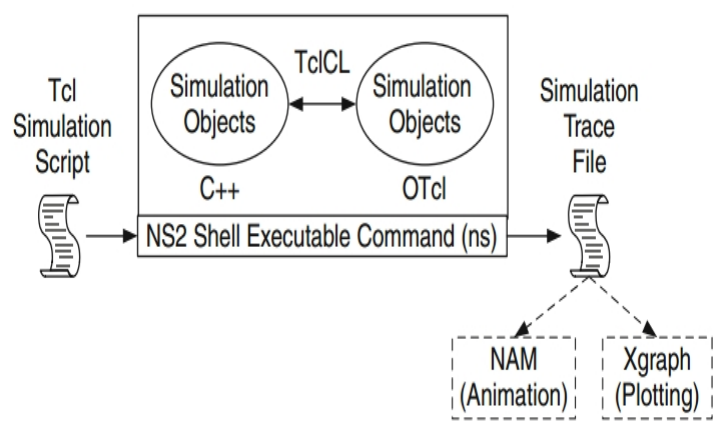

Gbr. 3 Arsitektur dasar NS-2

TclCL dan OTcl adalah komponen TCL berfungsi untuk menjembatani konfigurasi jaringan komunikasi dengan proses simulasi. NS-2 dieksekusi melalui perintah eksekusi command line. Hasil simulasi berupa catatan atau trace yang dapat dipergunakan oleh network animator (NAM) maupun plot grafik xgraph.

\section{E. Evalvid (Evaluasi video)}

NS-2 menyediakan presentasi data menggunakan xgraph. Namun xgraph kehilangan detail kejadian pengiriman data dan hanya menampilkan data rata-rata untuk parameter yang ditinjau. Sedangkan, untuk mempresentasikan parameter yang dievaluasi, penelitian ini menggunakan evalvid.

Evalvid adalah framework dan tool set untuk evaluasi kualitas video yang dikirimkan melalui jaringan komunikasi nyata atau simulasi [6]. Struktur dari framework evalvid ditunjuk Gambar 4 [7].

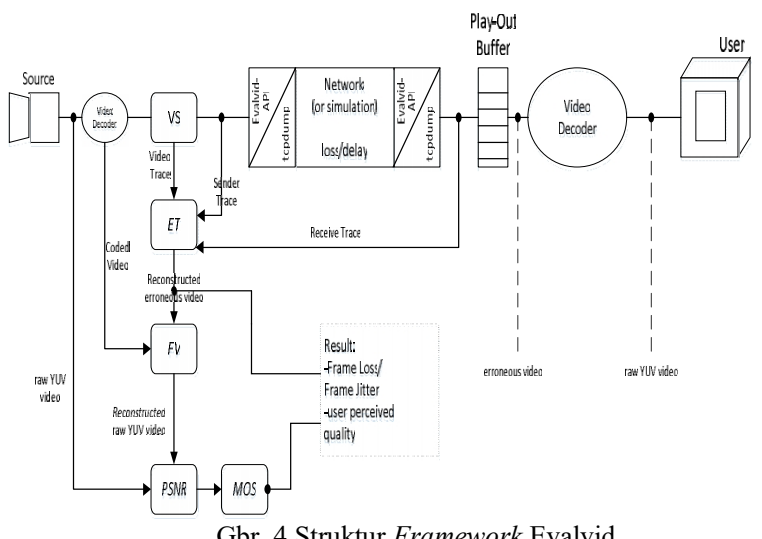

Komponen utama dari struktur evalvid dijelaskan sebagai berikut :

1. Source : sumber video dapat berupa raw file YUV dengan resolusi Quarter Common Intermediate Format (QCIF, $176 \times 144$ ) atau di Common Intermediate Format (CIF, 352 x 288).

2. Video Encoder dan Decoder : Evalvid mendukung dua codec MPEG4, yaitu codec NCTU dan ffmpeg. 
3. VS (Video Sender) : komponen VS membaca file video yang dikompres dari output encoder, menfragmentasi setiap frame video yang berukuran besar menjadi segmen yang berukuran kecil dan kemudian mengirimkan segmen ini melalui paket UDP (Unit Data Protocol) pada jaringan nyata atau simulasi. Untuk setiap pengiriman paket UDP, framework mencatat tanda waktu, id paket, dan ukuran paaket di sender trace file dengan bantuan tcp dump atau win dump, jika jaringan adalah link nyata. Namun, jika jaringan disimulasikan, sender trace file disediakan oleh entitas pengirim. komponen VS juga membangkitkan video trace file yang berisi informasi tentang settiap frame pada file video real. Video trace file dan sender trace file yang kemudian digunakan untuk evaluasi kualitas video berikutnya.

4. ET (Evaluate Trace) : Evaluasi berlangsung di sisi pegirim. Oleh karena itu, informasi tanda waktu, id packet, dan ukuran paket yang diterima pada penerima harus dikirim kembali ke pengirim. Berdasarkan file video asli yang dikodekan, file video trace, file sender trace, dan file received trace, komponen ET menghasilkan laporan delay dan packet loss serta file video rekonstruksi untuk melihat hasil video pada sisi penerima mengalami kerusakan atau tidak.

5. FV (Fix Video) : penilaian kualitas video digital dilakukan dari frame demi frame. Oleh karena itu, jumlah total frame video di sisi penerima, termasuk yang salah, harus sama seperti video asli di sisi pengirim.

6. PSNR (Peak Signal Noise Ratio) : PSNR adalah salah satu objek untuk menilai QoS aplikasi pada transmisi video.

7. MOS (Mean Opinion Score) : suatu subjektif untuk mengukur kualitas video digital pada aplikasi [8].

\section{HASIL DAN PEMBAHASAN}

Pada bab ini yang dibahas adalah hanya output penerima paket data pada simulasi NS-2 yang digunakan. Kemudian, untuk menganalisa kinerja non CDN dan meningkatkan kinerja CDN menerapkan Geo DNS dengan masing-masing uji coba dilakukan 20 kali skenario percobaan. Dalam pengujian dilakukan percobaan pengirim dan penerima paket data steraming video online dari server ke client. Parameter kinerja yang di ukur antara lain delay dan packet loss.

\section{A. Delay}

Delay adalah waktu tunda yang disebabkan oleh proses pentransmisian paket data steraming video online yang menjadi tujuannya. Rumus untuk mencari delay yaitu ;

Delay $=($ Waktu terima paket-Waktu kirim paket $)$

$$
\text { Jumlah paket }
$$

TABEL I

PERBANDINGAN DELAY NON CDN DAN CDN

\begin{tabular}{|c|c|c|}
\hline \multirow{2}{*}{ Percobaan } & \multicolumn{2}{|c|}{ Delay (s) } \\
\hline & Non CDN & Geo DNS \\
\hline 1 & 0,264373 & 0,06663 \\
\hline 2 & 0,280332 & 0,067416 \\
\hline 3 & 0,280363 & 0,067557 \\
\hline 4 & 0,280186 & 0,067609 \\
\hline 5 & 0,280338 & 0,067526 \\
\hline 6 & 0,279745 & 0,067829 \\
\hline 7 & 0,279691 & 0,067589 \\
\hline 8 & 0,280308 & 0,067721 \\
\hline 9 & 0,280371 & 0,067806 \\
\hline 10 & 0,280204 & 0,067829 \\
\hline 11 & 0,280373 & 0,06775 \\
\hline 12 & 0,280469 & 0,06741 \\
\hline 13 & 0,27929 & 0,067534 \\
\hline 14 & 0,280371 & 0,067584 \\
\hline 15 & 0,280281 & 0,06768 \\
\hline 16 & 0,279912 & 0,067609 \\
\hline 17 & 0,2803 & 0,067695 \\
\hline 18 & 0,279848 & 0,06777 \\
\hline 19 & 0,279644 & 0,067558 \\
\hline 20 & 0,279529 & 0,068076 \\
\hline Rata-Rata & 0,279296 & 0,067609 \\
\hline
\end{tabular}

Delay dapat dipengaruhi oleh jarak, besarnya paket kapasitas video dan waktu lama proses pengirim dan terima paket. Menurut versi TIPHON (Telecommunications and Single server Protocol Harmonization Over Networks), besarnya delay dapat diklasifikasikan pada tabel berikut :

TABEL II

DELAY MENURUT TIPHON

\begin{tabular}{|c|c|}
\hline Kategori Delay & Besar Delay \\
\hline Sangat bagus & $<150 \mathrm{~ms}$ \\
\hline Bagus & $150 \mathrm{~s} / \mathrm{d} 300 \mathrm{~ms}$ \\
\hline
\end{tabular}




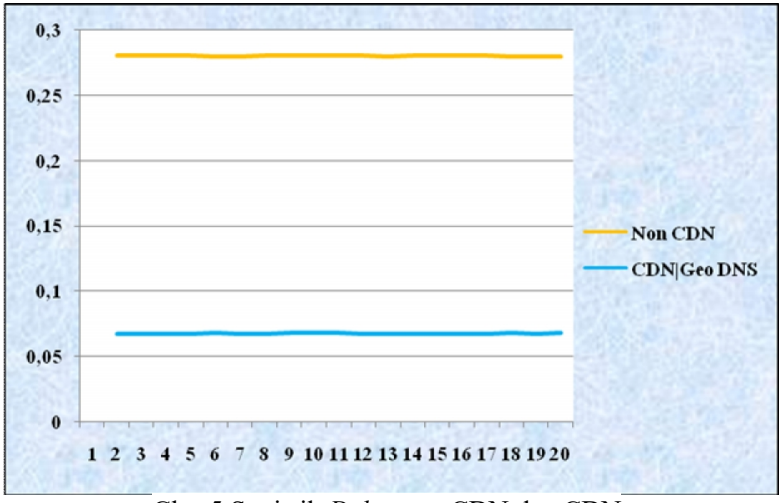

Gbr. 5 Statistik Delay non CDN dan CDN

Gambar menunjukan delay 20 kali skenario percobaan non CDN naik atau lebih besar. Sedangkan delay 20 kali skenario percobaan Geo DNS pada CDN lebih kecil/sedikit. Maka dengan diterapkan Geo DNS pada CDN jauh lebih baik dibandingkan non CDN.

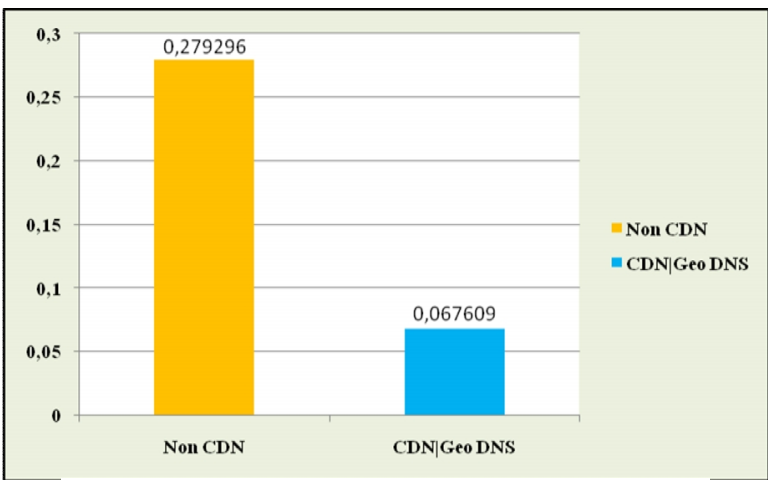

Gbr. 6 Perbandingan Rata-Rata Delay non CDN dan CDN

Menurut standart TIPHON, maka delay Geo DNS pada CDN masuk pada kategori sangat bagus $(<150$ $\mathrm{ms}$ ) dan nilai delay non $\mathrm{CDN}$ masuk pada kategori bagus (150 s/d $300 \mathrm{~ms})$.

Menurut versi TIPHON (Telecommunicationsand Single server Protocol Harmonization Over Networks). Tabel delay dapat diklasifikasikan sebagai berikut ;

TABEL III

DELAY Geo DNS pada CDN MENURUT TIPHON

\begin{tabular}{|l|c|}
\hline \multicolumn{1}{|c|}{ Kategori Delay } & Nilai Delay \\
\hline Sangat Bagus & $<150 \mathrm{~ms}$ \\
\hline Bagus & $150 \mathrm{~s} / \mathrm{d} 300 \mathrm{~ms}$ \\
\hline
\end{tabular}

\section{B. Packet loss}

Packet loss adalah jumlah paket data yang hilang saat proses pentransmisian terjadi. Rumus untuk mencari packet loss yaitu :

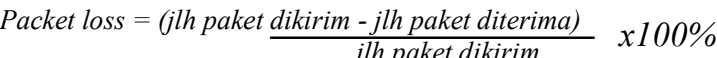

Hasil receive dari pentransmisian paket data streaming video online dapat dilihat pada tabel packet loss dibawah ini :
TABEL IV

PERBANDINGAN PACKET LOSS NON CDN DAN CDN

\begin{tabular}{|c|c|c|}
\hline \multicolumn{3}{|c|}{ Packet loss (\%) } \\
\hline \multirow[b]{2}{*}{ Percobaan } & \multirow{2}{*}{$\begin{array}{l}\text { Non } \\
\text { CDN }\end{array}$} & CDN \\
\hline & & $\begin{array}{c}\text { Geo } \\
\text { DNS }\end{array}$ \\
\hline 1 & $42.67 \%$ & $3.31 \%$ \\
\hline 2 & $44.00 \%$ & $3.99 \%$ \\
\hline 3 & $44.00 \%$ & $3.97 \%$ \\
\hline 4 & $44.00 \%$ & $3.62 \%$ \\
\hline 5 & $44.00 \%$ & $3.88 \%$ \\
\hline 6 & $44.00 \%$ & $3.47 \%$ \\
\hline 7 & $44.00 \%$ & $3.72 \%$ \\
\hline 8 & $44.00 \%$ & $3.83 \%$ \\
\hline 9 & $45.33 \%$ & $3.82 \%$ \\
\hline 10 & $44.00 \%$ & $3.73 \%$ \\
\hline 11 & $44.00 \%$ & $3.89 \%$ \\
\hline 12 & $44.00 \%$ & $3.79 \%$ \\
\hline 13 & $44.00 \%$ & $3.78 \%$ \\
\hline 14 & $44.00 \%$ & $3.56 \%$ \\
\hline 15 & $44.00 \%$ & $3.74 \%$ \\
\hline 16 & $44.00 \%$ & $3.97 \%$ \\
\hline 17 & $44.00 \%$ & $3.72 \%$ \\
\hline 18 & $44.00 \%$ & $3.54 \%$ \\
\hline 19 & $44.33 \%$ & $3.66 \%$ \\
\hline 20 & $49.67 \%$ & $11.42 \%$ \\
\hline Rata-Rata & $44.30 \%$ & $4.12 \%$ \\
\hline
\end{tabular}

Setelah data 20 kali hasil percobaan packet loss sudah di dapat. Maka dibuat Gambar statistik non CDN dan CDN sebagai berikut ini :

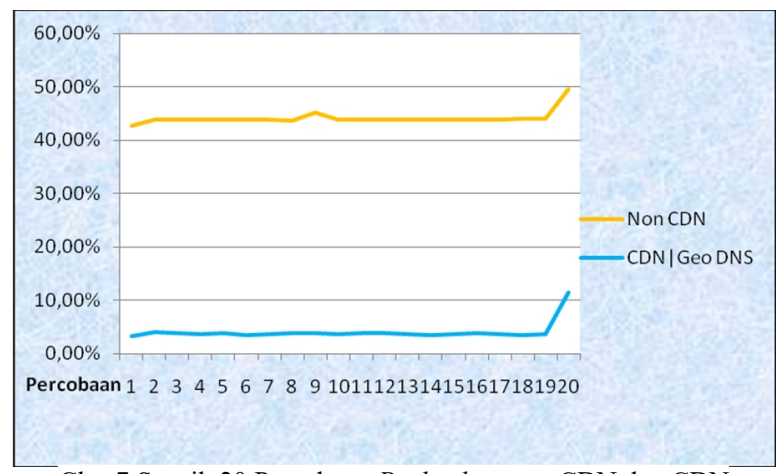

Gbr. 7 Stastik 20 Percobaan Packet loss non CDN dan CDN

Kemudian hasil gambar perbandingan rata-rata 20 kali skenario percobaan packet loss non CDN dan CDN dapat dilihat perbedaan dibawah ini: 


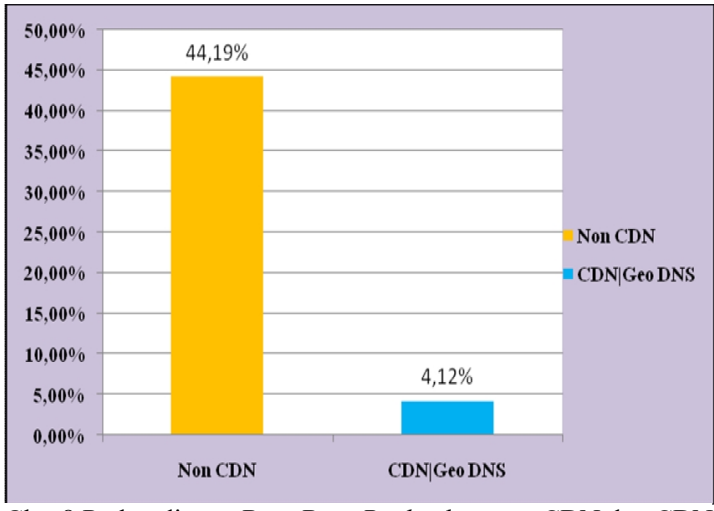

Gbr. 8 Perbandingan Rata-Rata Packet loss non CDN dan CDN

Menurut versi TIPHON (Telecommunicationsand Single server Protocol Harmonization Over Networks). Tabel packet loss dapat diklasifikasikan sebagai berikut ;

TABEL V

PACKET LOSS MENURUT TIPHON

\begin{tabular}{|l|c|}
\hline Kategori Packet loss & Nilai Packet loss \\
\hline Sangat Bagus & $0 \%$ \\
\hline Bagus & $3 \%$ \\
\hline Sedang & $15 \%$ \\
\hline Jelek & $25 \%$ \\
\hline
\end{tabular}

\section{KESIMPULAN DAN SARAN}

Kesimpulan yang dapat diambil dari menyelidiki yang telah dilakukan adalah sebagai berikut :

1. Hasil dari percobaan non CDN dibandingkan dengan menerapkan Geo DNS pada CDN jauh lebih baik delay dan packet loss lebih kecil.

2. Diterapkan Geo DNS pada CDN untuk meminimalisir jarak request client dengan server terdekat agar pengiriman paket data video streaming lebih cepat sampai ke user dan data yang dikirim atau diterima tidak mengalami kerusakan pada paket data.

\section{REFERENSI}

[1] S. Chen, "Content Delivery Network", Cina: Springer-Verlag, April 21, 1998.

[2] I. Gede, "Distribusi Konten Web Server Menggunakan Metode Cotent Delivery Network", Jurnal Sistem Informatika, vol. 160, pp. 159-169, Nov. 2015.

[3] M. J. Rajabi, "Analisa Literatur Jaringan," [Online], Fakultas Ilmu Komputer, Universitas Indonesia, 2008. Related:lib.ui.ac.id/file?file=digital/126425-T-642-

Analisa\%20pemanfaatanLiteratur.pdf [11 Februari 2016].

[4] N. Aine, and Omar, FSKKP alumni system, Diss. Universiti Malaysia Pahang, 2009.

[5] (2002) The IEEE website. [Online]. Available: http://www.ieee.org/

[6] M. Shell. (2002) IEEEtran homepage on CTAN. [Online]. Available: http://www.ctan.org/texarchive/macros/latex/contrib/supported/IEEEtran/

[7] FLEXChip Signal Processor (MC68175/D), Motorola, 1996.

[8] "PDCA12-70 data sheet," Opto Speed SA, Mezzovico, Switzerland. 